\title{
Kajian Makna Saka Guru di Masjid Gedhé Mataram Kotagede Yogyakarta (Sebuah Tinjauan Arsitektur)
}

\author{
Ajeng Kusuma \\ Departemen Teknik Arsitektur dan Perencanaan Universitas Gadjah Mada \\ E-mail: ajeng.kusumadewi@mail.ugm.ac.id
}

\begin{abstract}
Abstrak
Yogyakarta merupakan satu dari sekian banyak kota di Indonesia yang dikenal sebagai kota pelajar, kota ini juga berjuluk sebagai kota budaya. Hasil pertimbangan dari 14 kawasan konservasi di Yogyakarta mengerucut pada wilayah Kotagede sebagai salah satu cagar budaya. Eksistensi objek pusaka di Kotagede dianggap relatif baik dan masih terjaga keasliannya. Sejarah mencatat, para raja Nusantara pemeluk agama Islam berganggapan masjid sebagai pelengkap ibukota kerajaan. Konsepsi masjid-makam secara garis besar menjadi suatu sinergi yang tidak dapat terpisahkan dari sejarah Masjid Gedhé Mataram Kotagede sebagai masjid tradisional. Hal menarik dari Masjid Gedhé Mataram Kotagede yakni pada ruang utama terdapat empat tiang sebagai penopang atap, bernama saka guru. Saka guru tidak hanya dimaknai sebagai penopang struktur bangunan, tetapi memiliki makna simbolis tertentu sehingga menarik untuk dikaji. Penelitian menerapkan metode kualitatif dan berproses secara rasionalistik dengan pendekatan semiotika. Pendekatan semiotika model Saussure diggunakan sebab manusia cenderung memiliki keinginan untuk membuat signifikansi makna di atas segalanya. Manifestasi tanda membantu konstruksi utopia spiritual pada Saka Guru. Hasilnya berupa hubungan kosmos, terutama pengalaman manusia saat terkoneksi dengan arah vertikal menghubungkan dunia spatial dan alam kosmos. Saka Guru di Masjid Gedhé Mataram Kotagede memiliki dua orientasi yakni menuju arah kiblat serta arah vertikal menuju hubungan platonik dengan sang pencipta.
\end{abstract}

Kata kunci: itektur, Semiotika, Masjid, Saka Guru, Dualitas

\begin{abstract}
Yogyakarta is one of the many cities in Indonesia known as a city of students, Kotagede is also known as a city of culture. The results of consideration from 14 conservation areas in Yogyakarta converge on the Kotagede area as a cultural heritage. The existence of heritage objects in Kotagede is considered relatively good also their authenticity is still maintained. History records that the kings of the archipelago who were adherents of Islam considered the mosque to be a complement to the royal capital. The concept of the mosque-grave broadly becomes a synergy that cannot be separated from the history of the Gedhe Mataram Kotagede Mosque as a traditional mosque. An interesting thing about the Gedhe Mataram Kotagede Mosque is that in the main room where lies four pillars to support the roof, called the saka guru. Saka guru is not only interpreted as a support for the building structure but has a certain symbolic meaning that makes it interesting to study. This research applies qualitative methods and processes in a rationalistic mode with a semiotic approach. Saussure semiotic methods are used because humans tend to have the desire to make significance above anythings. The manifestation of signs helps construct a spiritual utopia in the Saka Guru. The result is a cosmic relationship, especially human experience when connected in a vertical direction relating the spatial world and the cosmic universe. Saka Guru at the Gedhe Mataram Kotagede Mosque has two orientations, first to Qiblat direction and the vertical direction towards the platonic relationship with the creator.
\end{abstract}

Keywords: Architecture, Semiotics, Mosque, Saka Guru, Duality. 


\section{Pendahuluan}

Daerah Istimewa Yogyakarta selain dikenal sebagai kota pelajar, kota ini juga disebut sebagai kota budaya. Pada era kolonial Yogyakarta merupakan daerah dengan sistem pemerintahan sendiri. Berjuluk Zelfbestuurlandschappen atau Wilayah Swapraja, yakni Kasultanan Ngayogyakarta Hadiningrat dan Kadipaten Pakualaman. Kasultanan Ngayogyakarta Hadiningrat didirikan oleh Pangeran Mangkubumi bergelar sultan Hamengku Buwana I di tahun 1755 sebagai penerus kerajaan Mataram Islam, didirikan oleh Panembahan Senopati (R. Danang Sutawijaya) sedangkan Kadipaten Pakualaman didirikan oleh Pangeran Notokusumo (saudara Sultan Hamengku Buwana II) bergelar Adipati Paku Alam I tahun 1813 (Priyono, 2015). Berdirinya kasultanan Yogyakarta serta perkembangan peradabannya tidak dapat terlepas dari hasil karya budaya yang dapat dinikmati hingga kini.

Wilayah ini memiliki nilai budaya yang selalu memikat untuk dikaji, terutama kawasan konservasi budaya. Berlandaskan hal itu konservasi tidak senantiasa berfokus terhadap bangunan serta situs saja tetapi mecangkup konservasi suatu kawasan. Terdapat 14 Kawasan Cagar Budaya di Daerah Istimewa Yogyakarta, ditetapkan dengan Surat Keputusan Dinas Kebudayaan DIY No. 188/ 38.A (DIY, 2015) menguatkan kedudukan Kawasan Cagar Budaya di DIY, yaitu: Kraton, Malioboro, Pakualaman, Kotagede, Kotabaru, Imogiri, Parangtritis, Pleret, Jetis, Pengok, Baciro, Prambanan, Ratu Boko, Sokoliman. Hasil pertimbangan dari 14 kawasan tersebut mengerucut pada wilayah Kotagede sebagai salah satu cagar budaya yang dianggap relatif baik dan masih terjaga keasliannya.

Kawasan Kotagede memiliki luas $220 \mathrm{Ha}$ serta menyimpan aset sejarah mengenai lahirnya Mataram Islam. Kerajaan Mataram Islam didirikan oleh Panembahan Senopati. Menurut Ricklefs (Ricklefs, 2005). Senopati meninggal sekitar tahun 1601 M dikebumikan di Kotagede, meskipun dokumentasi mengenai masa pemerintahannya kurang memuaskan namun dapat diterima bahwa masa ekspansi militer Mataram telah dimulai. Mataram Islam mencapai puncak kejayaan dimasa pemerintahan Sultan Agung di tahun 1613 hingga 1645 M. Kerajaan mataram mengambil Islam sebagai agama resmi. Terbukti pada gelar raja masa itu yakni Ngabdurrahman Sayidin Panatagama Khalifatullah ing Tanah Jawa. Gelar tersebut menunjukan indikasi peran agama di wilayah Kotagede. Kekuasaan raja tercermin didalamnya sebagai pemimpin agama sekaligus pemerintahan.

Sejarah mencatat, para raja Nusantara pemeluk agama Islam berganggapan masjid sebagai pelengkap ibukota kerajaannya. Bangunan masjid didirikan dekat keraton disebelah barat alunalun. Keberadaan alun-alun melambangkan sebagai lokasi bertemunya raja dengan rakyat, sedangkan masjid mengembalikan raja serta rakyat sebagai makhluk Tuhan yang setara. Masjid juga menjadi barometer kondisi masyarakat muslim dalam suatu ruang dan waktu. Bukti ideal ialah keberadaan bangunan Masjid Gedhé Mataram Kotagede sebagai salah satu perwujudan identitas fisik kawasan ini.

Masjid Gedhé Mataram Kotagede merupakan masjid utama kerajaan, didirikan di masa Panembahan Senopati. Masjid ini berlokasi satu komplek dengan Pasarean Agung Kotagede. Pasarean Agung menurut Silviana (Silviana, 2017) ialah pemakaman besar sebab sebagai lokasi permakaman tokoh-tokoh penting yakni para trah raja Mataram Islam. Bangunan masjid merupakan salah satu bangunan tertua non-candi di wilayah Yogyakarta. Beberapa perubahan telah terjadi terutama pada fisik Masjid Gedhé Mataram Kotagede seperti ekstensi bangunan serambi, benteng dan gapura dilakukan pada periode Sultan Agung. Tahun 1919 bangunan masjid terbakar kemudian dilaksanakan pemugaran di tahun 1932. Organisasi Muhammadiyah menambahkan tritisan di tahun 1926 serta penggantian material atap sirap dengan genteng di tahun 1950 .

Konsepsi masjid-makam secara garis besar Masjid Gedhé Mataram Kotagede terbagi menjadi empat bagian berupa bangunan utama, pagar batas keliling $(\mathrm{t}=2,5$ meter $)$, halaman dan makam. 
Keberadaan masjid-makam menjadi suatu sinergi yang tidak dapat terpisahkan dari sejarah Masjid Gedhé Mataram Kotagede sebagai masjid tradisional. Karakter masjid tradisional di Jawa secara umum yaitu berdenah persegi, memiliki pagar keliling, mihrab, mimbar pawestren, serambi, jagang atau kolam, serta pelengkap berupa bedhug. Hal menarik dari Masjid Gedhé Mataram Kotagede yakni pada ruang utama terdapat empat tiang sebagai penopang atap, bernama saka guru. Istilah ini berasal dari bahasa Sansekerta, saka artinya tiang dan guru berarti Utama. Saka guru dapat diartikan sebagai tiang utama penyangga struktur arsitektural. Menurut KBBI saka guru merupakan sesuatu yang menjadi penegak (negara dan sebagainya). Oleh sebab itu, saka guru tidak hanya dimaknai sebagai penopang struktur bangunan, tetapi memiliki makna simbolis tertentu sehingga menarik untuk dikaji.

Berdasarkan uraian diatas penelitian ini memiliki urgensi untuk mengungkap signifikansi makna dari saka guru. Penelurusan akan dilaksanakan guna memahami makna saka guru dalam arsitektur masjid sehingga terdapat persamaan persepsi dari generasi ke generasi. Tujuan penelitian yakni guna mendeskripsikan makna simbolis saka guru pada arsitektural Masjid Gedhé Mataram Kotagede serta menelaah interaksi simbolik dalam tinjauan tata ruang dan tata bangunan Masjid Gedhé Mataram Kotagede.

\section{Metode}

Penelitian menerapkan metode kualitatif dan berproses secara rasionalistik dengan pendekatan semiotika. Pengertian rasionalisme sendiri ilmu bersumber dari pemahaman intelektual yang dibangun atas kemampuan bernalar secara logis. Penelitian rasionalistik berangkat dari kerangka teori berdasarkan makna hasil penelitian sebelumnya, teori-teori, gagasan para ahli serta masih timbulnya berbagai masalah sehingga perlu diteliti lebih lanjut. Metode penelitian kualitatif adalah metode penelitian berlandaskan filsafat post-positivisme, diggunakan pada kondisi objek alamiah, (sebagai lawanya adalah eksperimen) dimana penelitian adalah sebagai suatu instrumen kunci, teknik pengumpulan data dilakukan triangulasi (gabungan), analisis data dan hasil penelitian kualitatif lebih menekankan makna daripada generalisasi (Sugiyono, 2016). Umumnya pendekatan kualitatif diterapkan untuk meneliti sejarah, tingkah laku, kegiatan masyarakat serta aktivitas sosial. Pada konteks sosial, masalah yang dibawa oleh peneliti masih gelap, dinamis dan kompleks. Permasalahan dalam pendekatan kualitatif bersifat sementara atau tetap aktif.

Pendekatan semiotika model Saussure diggunakan sebab manusia cenderung memiliki keinginan untuk membuat signifikansi makna di atas segalanya. Pemaknaan tersebut tidak bersifat mutlak melainkan berproses secara aktif. Makna tercipta melalui interprestasi tanda. Konstruksi antara makna dan tanda hanya bisa dipahami dari perspektif manusia yang menggunakannya. Tanda berupa kata-kata, gambar, suara, bau, rasa, atau objek tetapi hal itu tidak memiliki makna intrinsik dan menjadi tanda hanya jika kita menanamkannya dengan makna ( Hess-Lüttich, 2003). Segalanya dapat menjadi tanda selama manusia menafsirkannya sebagai 'penanda' sesuatu. Studi litelatur akan membantu peneliti memperoleh gambaran umum mengenai situasi sosial. Berlandaskan studi kasus Masjid Gedhé Mataram Kotagede, metode ini dianggap sesuai. Alasan utama yakni terdapat permasalahan kompleks, dinamis, holistik, serta penuh makna. Peneliti bermaksud memahami situasi secara mendalam dengan meninjau setiap gejala dalam objek penelitian. Dasar penggunaan metode kualitatif adalah para peneliti dapat menemukan dan memahami apa tersembunyi dibalik fenomena dan kadang kala sulit untuk dipahami secara memuaskan (Rahmat, 2009). Penyebab lainnya ialah bertujuan meningkatkan kompetensi peneliti menggali data dengan jumlah kasus yang tidak bisa ditentukan sebab bergantung pada ketersedian literasi serta teori. 


\section{Arsitektur Tradisional Jawa}

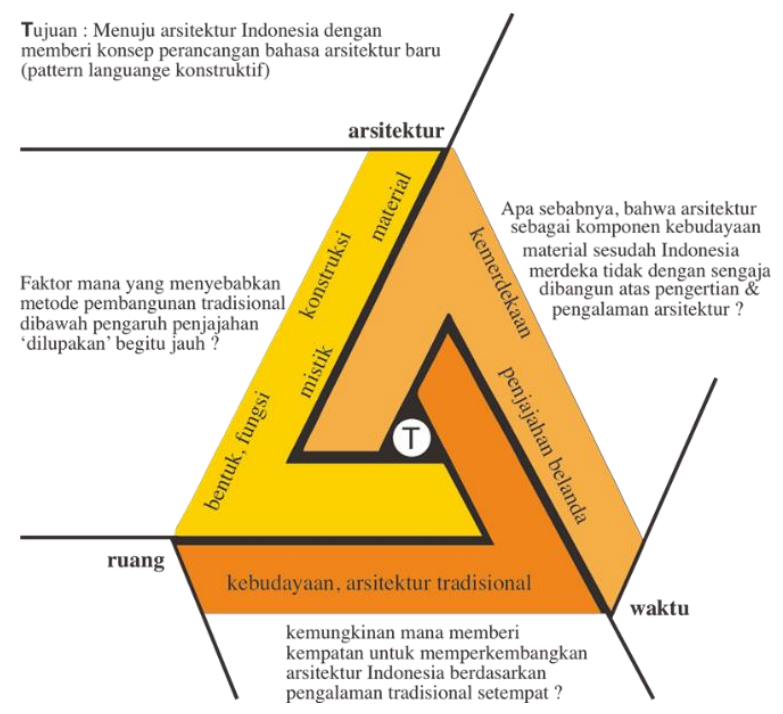

Gambar 1 Pengembangan konteks ruang, waktu dan arsitektur (Frick, 1977) dimodifikasi oleh Pribadi, 2020)

Arsitektur tradisional jawa merupakan salah satu langgam arsitektural yang kaya akan makna, baik dari sisi historis, keagamaan, kemasyarakatan, estetik dan simbolik (Prihantoro, 2005). Pada dasarnya arsitektur tradisional Jawa tidak dibuat tetapi hasil perkembangan pengalaman historis dalam konteks sebagai pernyataan suatu era kebudayaan Jawa. Meruntut periode arsitektur tradisional jawa bermula pada zaman neolitik, megalitik, purba, madya, VOC kemudian kemerdekaan. Jadi dapat disimpulkan bahwa arsitektur tradisional jawa merupakan sesuatu yang kompleks dan menyangkut beberapa disiplin ilmu berlandaskan periode masa. Menurut Heinz Frick (Frick, 1977) dalam bukunya berjudul "Pola Struktural dan Teknik Bangunan di Indonesia" menyatakan :

Persoalan arsitektur tidak boleh dianggap sebagai persoalan secara teknik atau fisik saja mengingat tingginya kebudayaan, patokan dan misik Jawa kuno dengan batasan yang dapat didefinisikan sesuai bidang tempat, waktu dan keggunaan.

Arsitektur tradisional Jawa menganggap bangunan tidak hanya berupa obyek fisik melainkan sebagai interprestasi simbol serta ritual. Arsitektur tradisional Jawa memiliki arti pembentukan didasari oleh bahan bangunan dan konstruksi dikoneksikan dengan pengaturan kosmis yakni tahap penyucian. Kosmologi Jawa menurut Pitana (Pitana, 2007) dimaknai sebagai konsep milik manusia Jawa tentang kepercayaan, mitos, norma, dan pandangan hidup dan di dalamnya terdapat keyakinan adanya jagad alit (mikrokosmos) dan jagad gede (makrokosmos). Berikut visualisasi makrokosmos dan mikrokosmos :

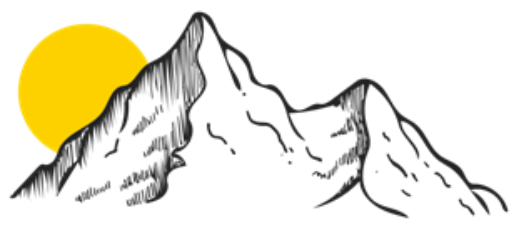

Makrokosmos : Lingkungan Alam

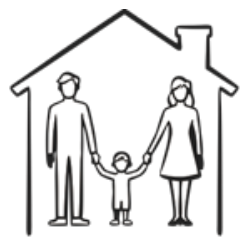

Mikrokosmos : Lingkungan Buatan

Gambar 2 Makrokosmos dan mikrokosmos ( Sumber: Frick 1977 dimodifikasi oleh Pribadi, 2020) 


\section{Arsitektur Jawa Zaman Madya}

Persebaran agama Islam di Indonesia dimulai paka awal abad ke-16 M melalui hubungan socio culture dengan para saudagar Arab dan Persia. Islam dengan nilai-nilainya yang tidak bertentangan dengan budaya masyarakat Jawa (culture) merupakan sub-culture yang mudah diterima oleh masyarakat (Rahman \& Hidayah, 2011) Penyebaran dilakukan melalui penayangan wiracarita Ramayana atau Mahabarata yang disisipi kalimat syahadat dan pembacaan Al-Quran. Hal ini yang mendasari penyebaran agama Islam terjadi secara bertahap bermula dari kota pantai utara menuju pedalaman Jawa. Dampaknya terjadi perwujudan akulturasi antara kebudayaan Hindu dengan Islam yang baik. Perubahan dari segi politis saling mempengaruhi, seperti pengaruh agama Islam dengan arsitektur tradisional Jawa.

Tabel 1 Kronologis Periode Islam Zaman Madya. ( Sumber: Frick 1977)

\begin{tabular}{|c|c|c|c|}
\hline \multirow[b]{2}{*}{$\begin{array}{l}\text { Tahun/ } \\
\text { Periode }\end{array}$} & \multirow[b]{2}{*}{$\begin{array}{c}\text { Kerajaan di Jawa \& Peristiwa } \\
\text { Politik }\end{array}$} & \multicolumn{2}{|c|}{ Manifest Kebudayaan } \\
\hline & & $\begin{array}{l}\text { Agama \& } \\
\text { Litelature }\end{array}$ & Arsitektur \\
\hline $1586 \mathrm{M}$ & & & $\begin{array}{l}\text { Kotagede/Plered } \\
\text { menjadi pusat } \\
\text { kekuasaan baru }\end{array}$ \\
\hline $1595-1597 \mathrm{M}$ & $\begin{array}{l}\text { Cornelis de Houtman masuk } \\
\text { melaui Jawa Barat }\end{array}$ & & \\
\hline $1584-1601 \mathrm{M}$ & $\begin{array}{l}\text { Panembahan Senopati Ingalaga } \\
\text { memerintah di Kotagede }\end{array}$ & & \\
\hline $1602 \mathrm{M}$ & $\begin{array}{l}\text { Dibentuknya } \\
\text { perdagangan Belanda (VOC) }\end{array}$ & & \\
\hline $1601-1646 \mathrm{M}$ & $\begin{array}{l}\text { Seda-ing-Krapyak memerintah di } \\
\text { Kotagede }\end{array}$ & & \\
\hline $1613-1646 \mathrm{M}$ & 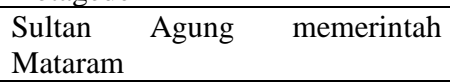 & & \\
\hline $1625 \mathrm{M}$ & & $\begin{array}{l}\text { Babad Tanah } \\
\text { Jawi }\end{array}$ & \\
\hline
\end{tabular}

\section{Definisi dan Fungsi Masjid}

Kata masjid berakar kata dari bahasa Arab yakni sajada-yasjudu-sujūdan berarti tunduk, patuh, ta'at, takzim dan hormat. Kurniawan (Kurniawan, 2014) menyatakan terbentuknya kata masjid menunjukkan arti tempat sujud (isim makan dari fi‘il sajada). Maka isim makan menunjukkan tempat untuk shalat diambil dari kata sujud. Istilah masjid merujuk pada tempat untuk sujud dengan penuh ketaatan karena akar katanya mengandung makna ta'at dan patuh, maka masjid sebenarnya tidak hanya berfungsi sebagai tempat ibadah tetapi merupakan tempat melakukan berbagai aktivitas yang mencerminkan makna ketundukan dan kepatuhan kepada sang pencipta (Rifa'i, 2016). Fungsi serta peran masjid ditentukan oleh lingkungan tempat dan zaman saat masjid didirikan. Menurut Kurniawan (Kurniawan, 2014) beberapa fungsi masjid pada masa dulu dan kini, di antaranya:

1. Tempat ibadah umat Islam, seperti shalat, dzikir, dan sebagainya.

2. Tempat menuntut ilmu umat Islam, yaitu ilmu agama dan ilmu umum.

3. Tempat memberi fatwa dan mengadili perkara.

4. Tempat menyambut tamu, rombongan, atau utusan.

5. Tempat melangsungkan pernikahan.

6. Tempat layanan sosial.

7. Tempat latihan perang.

8. Tempat layanan medis atau kesehatan. 


\section{Arsitektur Masjid Jawa}

Pembentukan atau perwujudan arsitektur Islam tergantung pada kecakapan tukang, kerajinan tangan serta pokok pembentukan tradisional secara konstruktif. Penentuan empat sudut, misalnya, hanya dengan empat tongkat atau batukali sudah dapat membentuk sebuah masjid atau Langgar. Alam sekitar dipilih sebagai perhiasan abstrak, sebagai pertunjukan dalam garis garis dan bidang bidang tertentu (Frick, 1977). Hal ini berkaitan dengan bidang arsitektur suatu masjid merupakan bidang suci untuk umat dengan upacara agamanya. Temboknya merupakan batasan dan tidak pernah dianggap sebagai sesuatu yang bergaya.

Karakteristik utama tipologi masjid Jawa ialah struktur utamanya. Struktur utama masjid Jawa menggunakan tiang induk dari kayu (saka guru) di tengah ruang salat utama untuk menopang atap. Budi (Budi, 2004) dalam jurnalnya tentang sejarah dan perkembangan Masjid Jawa, menguraikan :

Jumlah saka guru biasanya empat, tapi kadang enam atau delapan dan kadang hanya satu (saka tunggal). Struktur prinsip ini bersama dengan atap bertumpuk piramidal menyediakan ruang interior yang tinggi dan membentuk aksialitas vertikal yang kuat. Aksi aksial sentral dan vertikal yang kuat ini sebagai tandingan terhadap arah kiblat, memberikan dualitas dalam orientasi masjid di Jawa.

\section{Semiotika Model Saussure}

Pendekatan semiotika Saussure Model Saussure bersifat dua pihak atau dyadic, kombinasi antara konsep dengan gambar-suara merupakan suatu tanda. Menurut David Holdcroft (Holdcroft, 1991) metode semiotika Saussure melibatkan tanda dalam dua aspek, yaitu gambar-suara dan konsep. Saussure beranggapan tanda ialah penyatu keduanya dan dapat direpresentasikan pada figur berikut :

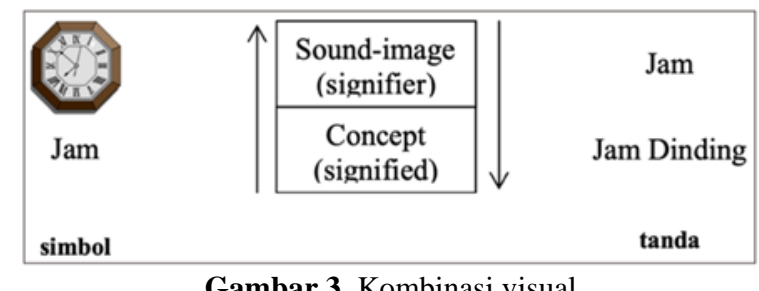

Gambar 3. Kombinasi visual

(Sumber : Hamid, 2011)

Hubungan antara keberadaan fisik tanda dan konsep dinamakan signifikasi, signifikansi ialah upaya dalam memberi makna terhadap dunia (Hamid, 2011). Guna menghilangkan ambiguitas ketiga gagasan, diperlukan perubahan istilah 'konsep' dan 'gambar-suara'. Saussure membagi tanda atas penanda (signifier) dan petanda (signified). Umumnya penanda (signifier) diartikan sebagai tanda berbentuk fisik serta dapat terdekteksi oleh indra manusia. Penanda dapat berupa sesuatu yang dapat didengar, dilihat, disentuh, dan dicicipi. Petanda (signified) adalah gambaran pemikiran atau konsep. Relasi keduanya terhubung secara psikologis serta dapat terjadi melalui norma konvensi, yakni kesepakatan sosial untuk memaknai tanda tersebut. Bahasa menurut Saussure adalah sistem istilah yang saling bergantung. Nilai setiap istilah berasal dari kehadiran simultan lain, seperti digambarkan dalam diagram relasi tanda :

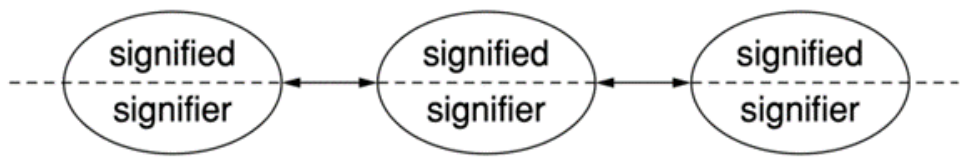

Gambar 4. Relasi antara tanda

(Sumber : Hess-Lüttich, 2003) 
Pemaknaan bergantung pada hubungan antara tanda, nilai suatu tanda didasari hubungan tersebut serta diatur dalam sistem paradoks :

a. Hal berbeda yang dapat ditukar dengan benda (x) yang nilainya ditentukan;

b. Hal serupa yang dapat dibandingkan dengan benda $(x)$ yang nilainya akan ditentukan.

Berdasarkan sistem tersebut, nilai dinyatakan tidak tetap selama terdapat pengakuan bahwa nilai dapat 'ditukar' dengan konsep atau makna tertentu. Komparasi harus dilakukan dengan nilai serupa yang memiliki pertentangan dengan nilai sebelumnya.

\section{Pembahasan}

Konfigurasi ruang Masjid Gedhé Mataram Kotagede terdiri dari ruang luar dan dalam. Tata ruang menurut Frick (Frick, 1977) dalam arsitektur Islam ialah menciptakan pembatasan bidang untuk kehidupan batin dan keagamaan. Jikalau diadakan pembentukan ruang, ruang tersebut terbentuk oleh bidang pembatasan (tenang, sebagai bujursangkar dan tidak terarah). Konsep ruang jika ditinjau dari arsitektur Jawa faktanya berbeda dengan konsep ruang menurut tradisi Barat. Tidak ada sinonim kata ruang dalam bahasa Jawa, yang mendekati ialah Nggon, kata kerjanya menjadi Manggon dan Panggonan berarti tempat (Kartono, 2005). Berdasarkan pemaparan tersebut penggunaan diksi tempat lebih tepat dari kata ruang. Pembagian tempat di bangunan Masjid Gedhé Mataram Kotagede terdiri atas bangunan utama atau Liwan, serambi dan emper. Secara keseluruhan denah bangunan berbentuk persegi berukuran $30 \times 30 \mathrm{~m}^{2}$. Terdiri dari empat buah kolom kayu atau Saka Guru yang membentuk suatu tempat ibadah dengan makna tertentu. Istilah ini berasal dari bahasa Sansekerta, saka artinya tiang dan guru berarti utama atau inti. Saka guru dapat diartikan sebagai tiang utama penyangga struktur arsitektural. Menurut KBBI saka guru merupakan sesuatu yang menjadi penegak (negara dan sebagainya). Saka Guru di Masjid Gedhé Mataram Kotagede memiliki dimensi 0,3 x 0,3 x 5 meter. Secara praktial berfungsi sebagai pendukung struktur atap berjenis tajuk lambing gantung. Berikut visualisasi penempatan Saka Guru di Masjid Gedhé Mataram :

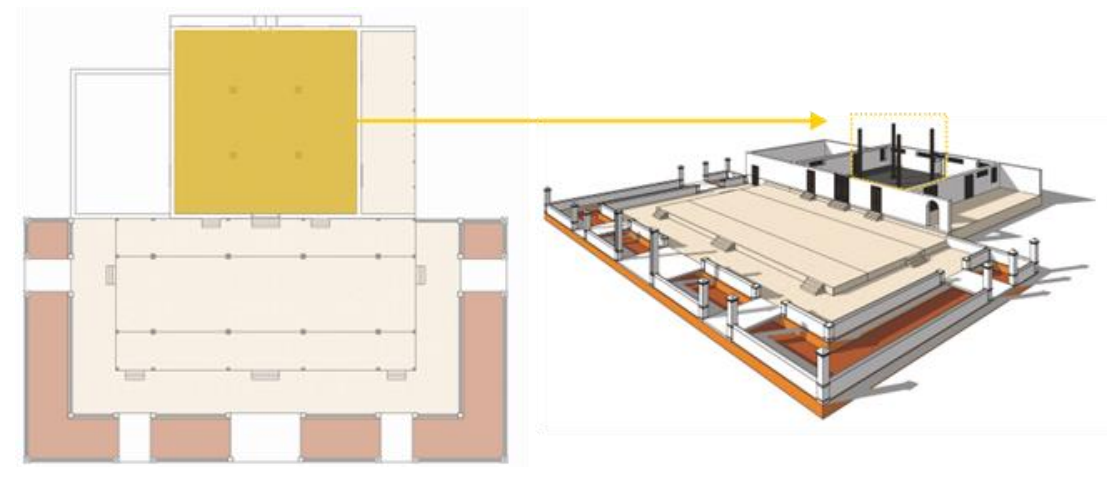

Gambar 5. Saka Guru di Masjid Mataram Kotagede (Sumber : Pribadi, 2020) 


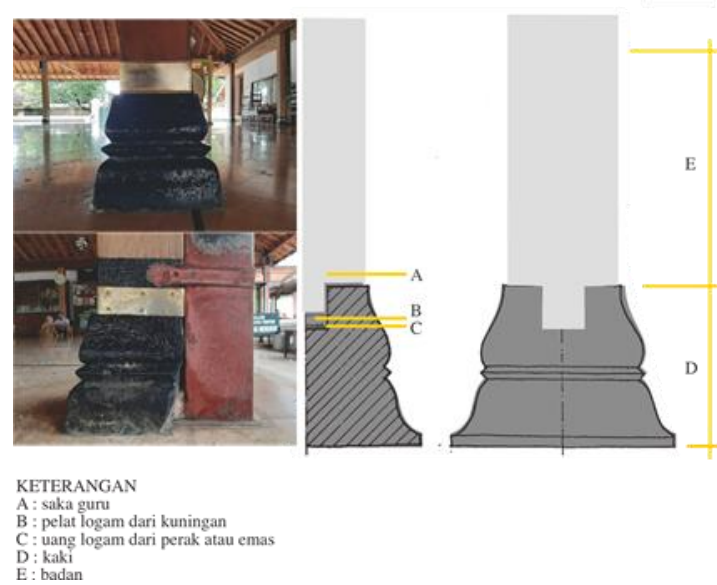

Gambar 6. Detail Umpak dan Saka Guru di Masjid Mataram Kotagede (Sumber : Pribadi, 2020)

Mayoritas konstruksi bangunan Masjid Gedhé Mataram Kotagede menggunakan kayu jati baik sebagai tiang penyangga bangunan maupun konstruksi atap. Kayu jati dikenal selain dari segi kekuatannya, pemilihan kayu jati secara simbolis bermakna khusus. Pemaknaan ini bermaksud agar manusia memiliki jati diri yang kuat. Pesan intinya ialah manusia harus memiliki jati diri yang kuat dalam menjalani lika-liku kehidupan tanpa meninggalkan ibadah kepada tuhan yang maha esa. Saka Guru dengan material kayu jati juga dapat dimaknai sebagai simbol kesejatian. Hal tersebut semestinya tidak semata dimaknai sebagai jati diri, tetapi kesejatian secara universal. Keimanan yang sejati, cinta yang sejati, kesetiaan yang sejati sehingga kayu jati bisa dimaknai sebagai kesejatian dalam banyak hal untuk menangkal sikap dan perilaku munafiq, khianat serta ketidaksungguhan (Abror, 2016). Relasi antara Saka Guru dengan arsitektur masjid merupakan perwujudan yang berhubungan dengan kepercayaan serta makna metafisik. Berikut visualisasi perwujudan dualisme Saka Guru dan arah vertikal antara manusia dengan kekuatan markokosmos

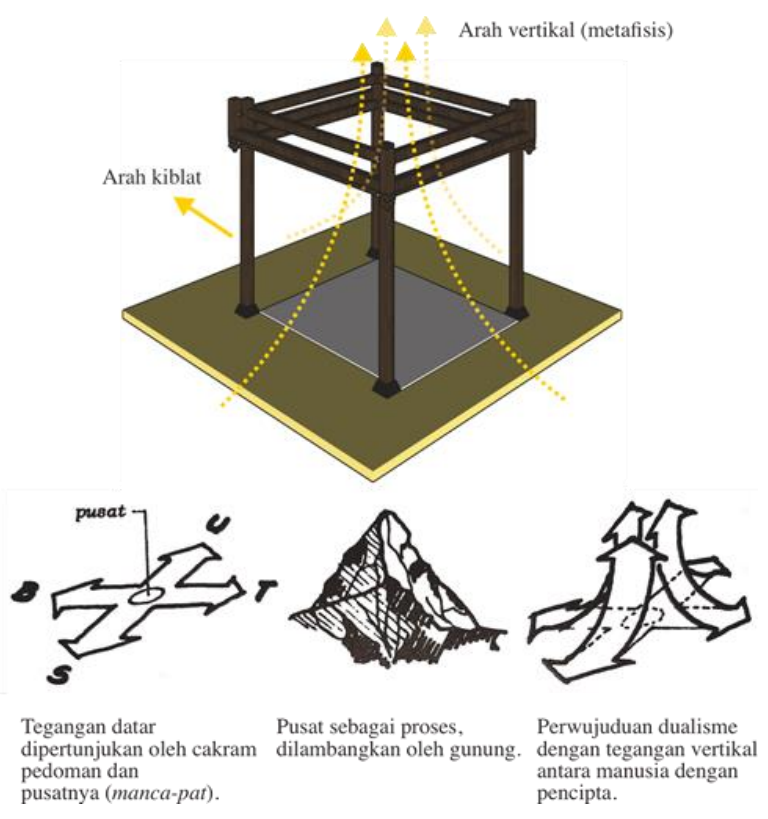

Gambar 7. Makna mistik Saka Guru

( Sumber: Frick 1977 dimodifikasi Pribadi, 2020) 
Berlandaskan konteks empat-lima (manca-pat) yang tidak mengandung batasan teritorial. Ruang di dalam Saka Guru membentuk suatu koneksi kehidupan sosial dan keagamaan. Keagamaan dengan konteks pragmatis yakni sesuai dengan pengalaman spiritual masing-masing individu. Manifestasi manca-pat berbentuk pedoman cakram datar muncul (gambar paling kiri) sebagai arus ke atas dari gunung kemudian arah vertikal. Elemen tersebut didemontrasikan untuk mengatur emosi manusia serta membantu dalam konstruksi utopia spiritual secara platonik. Hasilnya berupa hubungan kosmos, terutama pengalaman manusia saat terkoneksi dengan arah vertikal menghubungkan dunia spatial dan alam kosmos. Manifestasi diatas terdapat signifikansi makna Saka Guru dalam bangunan Masjid Gedhé Mataram Kotagede, yakni :

1. Secara praktis, Saka Guru sebagai penopang atap.

2. Secara metafisik, Saka Guru memiliki sifat dualitas atau mendua.

Berdasarkan signifikansi makna Saka Guru jika ditinjau lebih jauh dari pendekatan semiotika model Saussure terdapat pemaknaan yang berproses secara aktif. Makna tersebut tercipta melalui interprestasi tanda. Berikut diagram matriks mengenai pemaknaan pertanda dan penanda dalam semiotika Saussure :

Tabel 2. Matriks Saka Guru ditinjau dari semiotika model Saussure (Sumber : Pribadi, 2020)

\begin{tabular}{|c|l|l|l|}
\hline Signifier & \multicolumn{1}{|c|}{ Lingustik } & Fisik (material) & \multicolumn{1}{c|}{ Fisik (bentuk) } \\
\hline Konsep Praktis & $\begin{array}{l}\text { Saka = tiang dan Guru } \\
\text { utama atau inti. } \\
\text { Kaka guru dapat diartikan } \\
\text { Kebagai tiang utama. }\end{array}$ & $\begin{array}{l}\text { Kayu jati dinilai } \\
\text { dari segi ketahanan } \\
\text { dan kekuatannya. }\end{array}$ & $\begin{array}{l}\text { Kolom penyangga struktur atap } \\
\text { berjenis tajuk lambing gantung. }\end{array}$ \\
\hline Metafisik & $\begin{array}{l}\text { Saka Guru merupakan } \\
\text { sesuatu yang menjadi } \\
\text { penegak negara. }\end{array}$ & $\begin{array}{l}\text { Simbol kesejatian, } \\
\text { sebagai jati diri, } \\
\text { tetapi kesejatian } \\
\text { secara universal. }\end{array}$ & $\begin{array}{l}\text { Konteks empat-lima (manca- } \\
\text { pat) memiliki sifat dualitas atau } \\
\text { mendua dalam orientasi masjid. } \\
\text { Orientasi arah kiblat dengan } \\
\text { arah vertikal bermakna } \\
\text { metafisik yang menciptakan } \\
\text { pertentangan. }\end{array}$ \\
\hline
\end{tabular}

\section{Simpulan}

Keberadaan Saka Guru di Masjid Gedhé Mataram Kotagede memiliki fungsi sebagai kolom penyangga struktur atap berjenis tajuk lambing gantung. Hal tersebut sejalan dengan diksi Saka Guru sebagai tiang utama. Definisi Saka Guru secara konsep merupakan sesuatu yang menjadi penegak negara atau pemerintahan. Saka Guru memiliki makna yang bersifat dualitas atau mendua. Konsep metafisik menjadi sebuah obyek yang menarik sebab memiliki relasi erat dengan konteks arah vertikal dalam empat-lima (manca-pat). Saka Guru memiliki dua orientasi yakni menuju arah kiblat serta arah vertikal menuju hubungan platonik dengan sang pencipta. 


\section{Daftar Pustaka}

Abror, I. (2016). Aktualisasi Nilai-nilai Budaya Masjid Pathok Negoro. Esensia, 63-79.

Budi, B. S. (2004). A Study on the History and Development of the Javanes Mosque. Journal of Asian Architecture and Building Engineering, 189-195.

DIY, P. P. (2015). Penetapan RKPD DIY 2015 Perubahan. Diambil kembali dari BAPPEDA DIY: http://bappeda.jogjaprov.go.id/download/index?page=27\&per-page $=10$

Frick, H. (1977). Pola Struktural dan Teknik Bangunan di Indonesia. Yogyakarta: Kanisius.

Hamid, F. (2011). Semiotika, Tanda dan Makna. Diambil kembali dari Universitas Mercu Buana: http://mercubuana.ac.id/files/SemiotikaPeriklanan/Modul 8 - Semiotika Periklanan.pdf

Hess-Lüttich, E. W. (2003). Semiotics: The Basics: Review of Chandler, Daniel. Journal of Pragmatics, 927-930.

Holdcroft, D. (1991). Saussure Sign, System, and Arbitrariness. Inggris: Cambridge University Press.

Kartono, J. L. (2005). Konsep Ruang Tradisional Jawa dalam Konteks Budaya. Dimensi Interior, 124-136.

Kurniawan, S. (2014). Masjid Dalam Lintasan Sejarah Umat Islam. Jurnal Khatulistiwa, 169-184.

Pitana, T. S. (2007). Reproduksi Simbolik Arsitektur Tradisional Jawa : Memahami Ruang Hidup Material Manusian Jawa. Gema Teknik, 126-133.

Prihantoro, A. (2005). Pasar Seni di Jogjakarta: Preseden Arsitektur Tradisional Jawa. Yogyakarta: Perpustakaan FTSP UII.

Priyono, U. (2015). Yogyakarta "City of Philosophy. Yogyakarta: Dinas Kebudayaan Daerah Istimewa Yogyakarta.

Rahman, A. A., \& Hidayah, K. (2011). Islam Dan Budaya Masyarakat Yogyakarta Ditinjau Dari Perspektif Sejarah. El Harakah, 46-59. https://doi.org/10.18860/el.v0i0.2019

Rahmat, P. S. (2009). Penelitian Kualitatif. Equilibrium, 1-8.

Ricklefs, M. C. (2005). Sejarah Indonesia Modern 1200-2004. Jakarta: Serambi. https://centerformunawareducation.files.wordpress.com/2013/06/sejarah-indonesiamodern-1200-2004.pdf

Rifa'i, A. (2016). Revitalisasi Fungsi Masjid Dalam Kehidupan Masyarakat Modern. Universum, 155-163.

Silviana, N. (2017). Makna dan fungsi arsitektur masjid gedhe mataram kotagede yogyakarta. Yogyakarta: perpustakaan Universitas Islam Negri Sunan Kalijaga Yogyakarta. http://digilib.uin-suka.ac.id/29787/2/13520023_BAB-I_IV-atau-V_DAFTAR-

PUSTAKA.pdf

Sugiyono. (2016). Metode Penelitian Kuantitatif, Kualitatif, dan R\&D. Bandung: Alfabeta. 